\title{
Efecto de un biofertilizante en el crecimiento y rendimiento de dos variedades de Medicago sativa
}

\section{Effect of a biofertilizer on the growth and yield of two varieties of Medicago sativa}

\author{
Rosa Marilin Vigo Pizarro'
}

\section{RESUMEN}

El objetivo del presente trabajo fue determinar el efecto de un biofertilizante en el crecimiento y rendimiento en dos variedades de Medicago sativa "alfalfa", se elaboró un biofertilizante a base de agua de lavado de café, excreta de vacuno, melaza y B-Lac ${ }^{\circledR}$, él que luego fue aplicado a dos variedades de alfalfa Cuf 101 y Beacon en $1 \%$ y 1.5\%. Se tuvo 6 tratamientos los que fueron distribuidos bajo un diseño completamente al Azar: T1 ( $0 \%$ Biof, Cuf 101), T2 (0\% Biof, Beacon), T3 (1\% Biof, Cuf 101), T4 (1\% Biof, Beacon), T5 (1.5\% Biof, Cuf 101) у T6 (1.5\% Biof, Beacon). Se evaluó parámetros productivos y bromatológicos. Los datos se analizaron mediante el análisis de varianza (ANVA), con el uso del programa estadístico Statistix versión 8.0, con un nivel de significancia $(\alpha)$ del $5 \%$ y un nivel de confianza $(1-\alpha)$ del $95 \%$ y la comparación de medias mediante el método de Dunnett $(\alpha=0.05)$. Se obtuvieron diferencias significativas para rendimiento $(1.42 \mathrm{~kg})$, altura de planta $(66 \mathrm{~cm})$, proteína $(23 \%)$ y digestibilidad (81\%), para número de hojas por planta, contenido materia seca, Fibra detergente neutro y ácido no se observaron diferencias significativas entre los tratamientos. Se concluye que el biofertilizante al $1.5 \%$ da mejor resultado.

Palabras clave: Biofertilizante, crecimiento de alfalfa.

\begin{abstract}
The objective of this work was to determine the effect of a biofertilizer on the growth and yield in two varieties of Medicago sativa "alfalfa", a biofertilizer based on coffee washing water, beef excreta, molasses and B-Lac ${ }^{\circledR}$ was elaborated, which then It was applied to two varieties of alfalfa Cuf 101 and Beacon in 1\% and 1.5\%. There were 6 treatments which were distributed under a completely Random design: T1 (0\% Biof, Cuf 101), T2 (0\% Biof, Beacon), T3 (1\% Biof, Cuf 101), T4 (1\% Biof, Beacon), T5 (1.5\% Biof, Cuf 101) and T6 (1.5\% Biof, Beacon). Productive and bromatological parameters were evaluated. The data were analyzed using the analysis of variance (ANVA), using the statistical program Statistix version 8.0, with a significance level $(\alpha)$ of $5 \%$ and a confidence level $(1-\alpha)$ of $95 \%$ and the comparison of means by Dunnett's method $(\alpha=0.05)$. Significant differences were obtained for yield $(1.42 \mathrm{~kg})$, plant height $(66 \mathrm{~cm})$, protein $(23 \%)$ and digestibility $(81 \%)$, for the number of leaves per plant, dry matter content, neutral and acid detergent fiber, no differences were observed significant between treatments. It is concluded that the $1.5 \%$ biofertilizer gives better results.
\end{abstract}

Keywords: Biofertilizer, alfalfa growth.

${ }^{1}$ Bachiller en Ingeniería Zootecnista. Universidad Nacional Toribio Rodríguez de Mendoza de Amazonas. 


\section{INTRODUCCIÓN}

Las industrias agropecuarias y agroindustriales generan importantes volúmenes de residuos sólidos y líquidos. En forma creciente ha aumentado los costos de disposición de tales residuos lo que ha generado también un incremento de los costos generales de tales empresas, los residuos sólidos al acumularse y no reincorporarse a la naturaleza en un corto o mediano plazo genera contaminación. La contaminación afecta al suelo, aire, ríos, lagos, mares, animales y a las personas. Los problemas de salud pública causados por la acumulación de los residuos sólidos urbanos a cielo abierto son numerosos. Sin mencionar las graves afectaciones al mismo medio ambiente. (Rodríguez y Córdova, 2006).

Es importante destacar que muchos de los compuestos presentes en estos residuos orgánicos son difíciles de degradar por los consorcios microbianos empleados en las plantas de tratamiento urbanas. (Rodríguez, 2010).Es por esto que, para obtener altas eficiencias en la remoción del material orgánico se requeriría tecnología sofisticada en el tratamiento de los efluentes, removiendo la alta carga orgánica que hay en ellos pero generando lodos que también necesitaría un tratamiento final, lo que en consecuencia involucraría una gran inversión en cada área en la que se genere este tipo de residuos agropecuarios. Por ello, lo más viable en la búsqueda de una solución a la problemática del tratamiento adecuado de los efluentes del café y excretas de vacuno resulta en generar un producto a partir de los mismos que les otorgue valor agregado además de eliminar el impacto ambiental que generaría su mala disposición final.

El B-Lac ${ }^{\circledR}$ es un producto comercial de inocuidad microbiológica, al estar compuesto por Lactobacillus y haber ausencia relativa de mohos, coliformes fecales y coliformes totales en su composición (Guccione, 2009), debido al pH ácido de 3.5 que ellos mismos generan y son capaces de tolerar, manteniéndose estables por periodos prolongados además su uso en producción de biofertilizantes transforma las excretas del ganado en un producto inocuo, ya que activa $y$ hace desarrolla la fermentación homoláctica (Román, 2012). Se utiliza además en ganadería y agricultura para la reducción de olores desagradables y como enmienda orgánica, respectivamente.

La Melaza de caña es un efluente de la industria azucarera mediante cristalización repetida final, de la cual no se puede extraer más azúcar por métodos físicos (Garassini, 1958). Resulta ser la materia prima más barata y adecuada en los países productores de azúcar (Crueger y Crueger, 1993).En pruebas de fermentación aporta con la energía necesaria para activar el metabolismo microbiológico, para que el proceso se potencialice, además de aportar minerales y aminoácidos (Restrepo, 2007).

Respecto a la utilización de mucílago de café en la producción de abonos, se ha elaborado abonos líquidos orgánicos sustituyendo el agua de la formulación inicial por mucílago. En algunos casos, debido al nitrógeno presente en el abono, el producto podría ser utilizado como inductor del crecimiento en una dosis de $10 \%$ a $30 \%$, indicando que se encontraría en una escala intermedia con respecto a la calidad del abono comercial. Además, al analizar los costos de producción es posible que el abono orgánico con aguas de lavado de café tenga un costo menor que el comprar fertilizante líquido comercial y por lo tanto, el productor ahorraría por ciclo vegetativo en el cultivo de hortalizas (Blandon, 2013). En este contexto, la presente investigación plantea la innovación de una técnica en la elaboración de fertilizante orgánico mediante fermentación láctica de las aguas de lavado de café y excretas de vacuno, que permita la revalorización de estos residuos.

\section{MATERIAL Y MÉTODO}

La investigación se realizó en dos etapas: elaboración del biofertilizante a nivel de laboratorio y la segunda aplicación del biofertilizante a nivel de campo en la Estación experimental - El Oratorio INIA, de la Facultad de Ingeniería Zootecnista Agronegocios y Biotecnología de la Universidad Nacional Toribio Rodríguez de Mendoza de Amazonas, ubicad en el distrito de Luya provincia de Luya, región Amazonas.

La metodología experimental fue la siguiente:

\section{a. Elaboración del biofertilizante}

Para la preparación de $900 \mathrm{~g}$ de mezcla para el abono foliar se siguió la metodología de Peralta (2010): la mezcla no debe presentar mal olor y tampoco olores fuertes, en cuanto a apariencia no debe presentar formación de capas de microorganismos, sea mohos o levaduras.

La pulpa de café se dejó fermentar por un periodo de treinta días con agua destilada, en un balde de plástico de cinco litros.

En un envase de plástico de 1 litro, se agregó $60 \%$ del agua de café anteriormente fermentado, 15\% de excreta de vacuno, $15 \%$ de melaza y $10 \%$ deBLac ${ }$ finalmente se mezcló homogéneamente. A esta mezcla se selló con una bolsa plástica para evitar la presencia de aire dentro del recipiente pues lo que se quería es conseguir un ambiente anaeróbico para la fermentación.

La mezcla fue llevado a una estufa a una temperatura de $40^{\circ} \mathrm{C}$ por cinco días, al quinto día se prensó la mezcla. El biol se almacenó a temperatura ambiente y 
cada cinco días se tomó lectura de $\mathrm{pH}$, por treinta días para determinar la estabilidad de la mezcla.

\section{b.Aplicación del biofertilizante orgánico}

Se tomó $270 \mathrm{~m} 2$ de la alfalfa ya instalada en Luya, se bordeó 18 parcelas de $3 \times 5 \mathrm{~m} 2$, nueve parcelas por cada variedad. Cada 7 días se agregó el biofertilizante. En la variedad Cuf 101 el T1 se utilizó (400 $\mathrm{ml}$ de agua), T2 $(397 \mathrm{ml}$ de agua $+3 \mathrm{ml}$ de biofertilizante) y T3 $(394 \mathrm{ml}$ de agua $+6 \mathrm{ml} \mathrm{de}$ biofertilizante); para la variedad Beacon el T4 se utilizó (400 $\mathrm{ml}$ de agua), T5 $(397 \mathrm{ml}$ de agua $+3 \mathrm{ml}$ de biofertilizante) y T6 $(394 \mathrm{ml}$ de agua $+6 \mathrm{ml} \mathrm{de}$ biofertilizante)

\section{c. Evaluación de parámetros productivos de alfalfa}

Rendimiento de forraje verde $\mathrm{kg} / \mathrm{m} 2$, para la determinación de este parámetro se utilizó un cuadrante de madera de $1 \mathrm{~m} \times 1 \mathrm{~m}$, se tomaron tres muestras al azar por cada unidad experimental, estas muestras se pesaron en una balanza para finalmente promediar dichos pesos.

Altura de planta, se tomó cinco medidas representativas de plantas de alfalfa por cada unidad experimental y se midió con una wincha desde la base hasta el punto más alto de la planta sin estirar las hojas, este valor se tomó al momento del corte.

Número de hojas por planta, se tomó cinco plantas por cada unidad experimental a las que se contó el total de las hojas y luego se promedió, este conteo se realizó solo al momento del corte.

Contenido materia seca De cada muestra que se obtuvo para calcular rendimiento de forraje verde $\mathrm{kg} / \mathrm{m} 2$ se tomó 100 gr y se colocó a una estufa a $70^{\circ} \mathrm{C}$ por 24 horas (para evaluar su contenido de materia seca y humedad.

\section{d. Análisis bromatológico proximal}

Las mismas muestras evaluadas en rendimiento de forraje fueron secadas en una estufa a $60^{\circ} \mathrm{C}$ por 24 horas. Luego fueron molidas en un molino eléctrico Retsch GM 200, finalmente las muestras fueron llevadas al Laboratorio de Nutrición para su análisis proximal de proteína y DIVMS (digestibilidad de materia seca), además de Fibra detergente neutro y ácido según la metodología de Van Soest, (1967).

\section{RESULTADOS}

Los gráficos 1, 2, 3, y 4 muestran los valores encontrados para rendimiento, altura de planta, proteína y digestibilidad. En base a las comparaciones múltiples (Dunnett $\alpha=0.05$ ), se observó efecto significativo para dichas variables es decir que los niveles de fertilizante y la variedad de alfalfa no producen los mismos resultados, el tratamiento T6 (1.5\% Biof, Beacon) fue el mejor tratamiento para: rendimiento $(1.34,1.42 \mathrm{~kg})$, altura de planta $(61,66 \mathrm{~cm})$, proteína $(22,23 \%)$ y digestibilidad $(80,81 \%)$, para primer y segundo corte respectivamente. Seguido del tratamiento T5 (1.5\% Biof, Cuf 101).

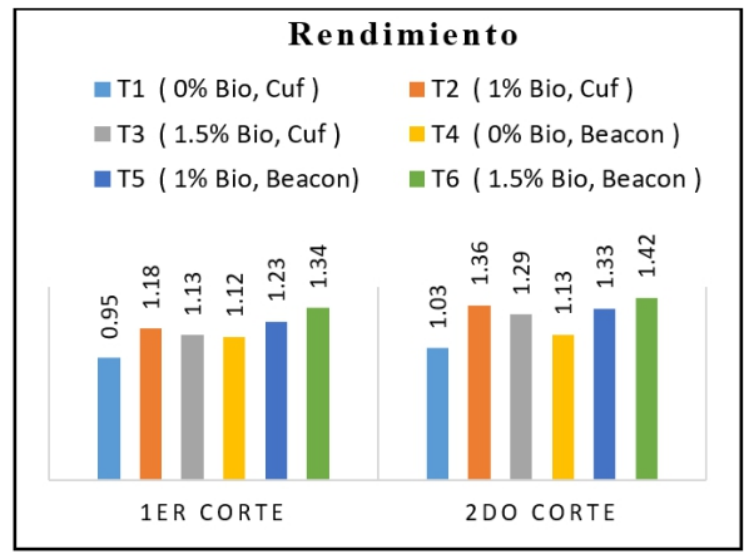

Figura 01. Rendimiento del primer y segundo corte

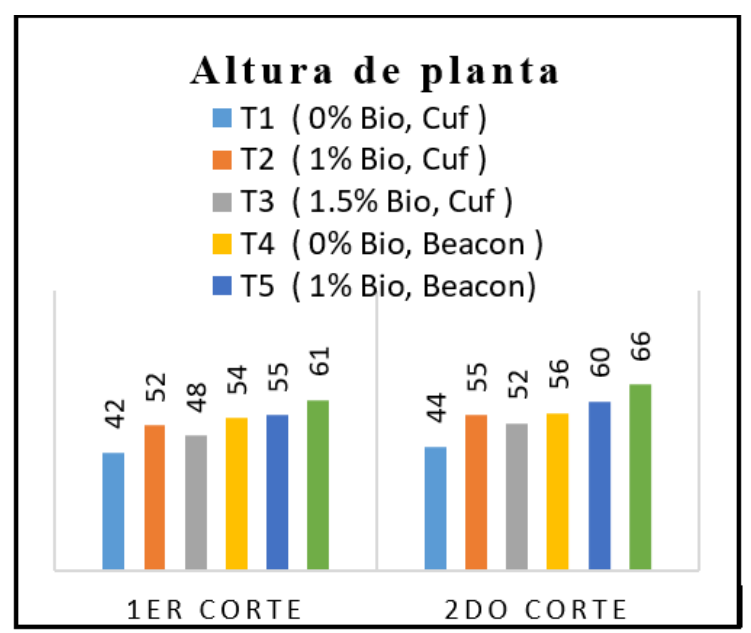

Figura 02. Altura de planta $(\mathrm{cm})$ del primer y segundo corte

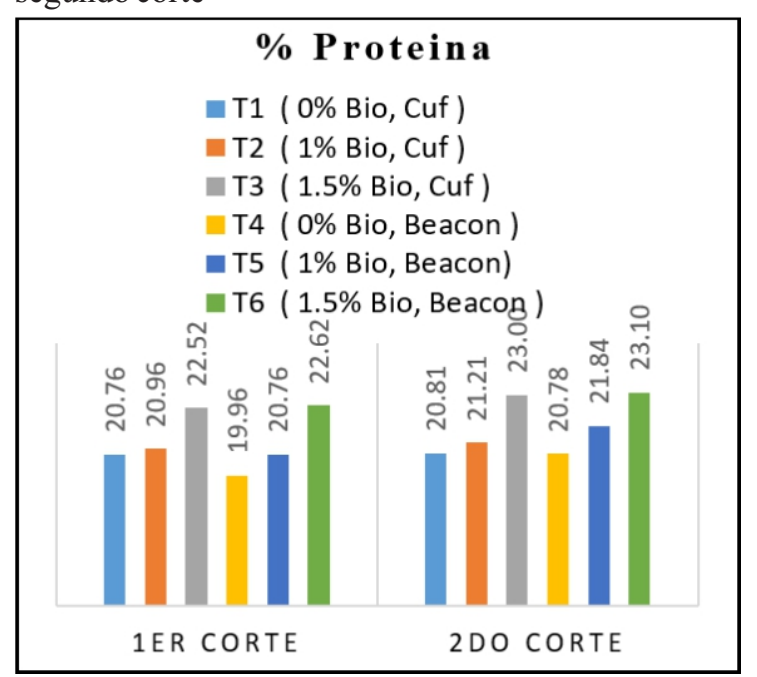

Figura 03. \% proteína del primer y segundo corte 


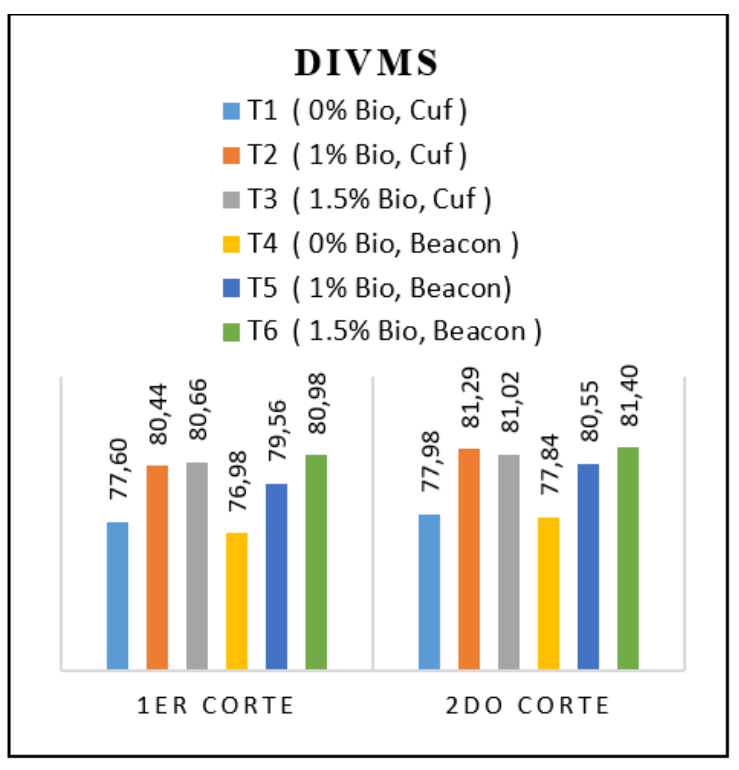

Figura 04. \% DIVMS del primer y segundo corte

Asimismo, los gráficos 5, 6, 7 y 8 muestran los valores encontrados para número de hojas por planta, materia seca, fibra detergente acida y neutra. En base a las comparaciones múltiples (Dunnett $\alpha=0.05$ ), no se observó efecto significativo para dichas variables es decir que los niveles de fertilizante y la variedad de alfalfa producen los mismos resultados, sin embargo se observa diferencias numéricas entre los tratamientos.

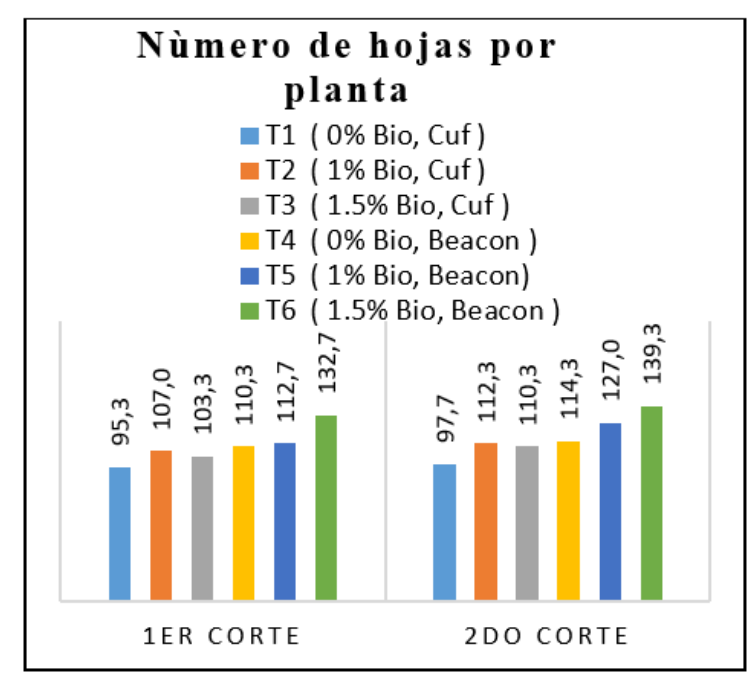

Figura 05. Número de hojas del primer y segundo corte

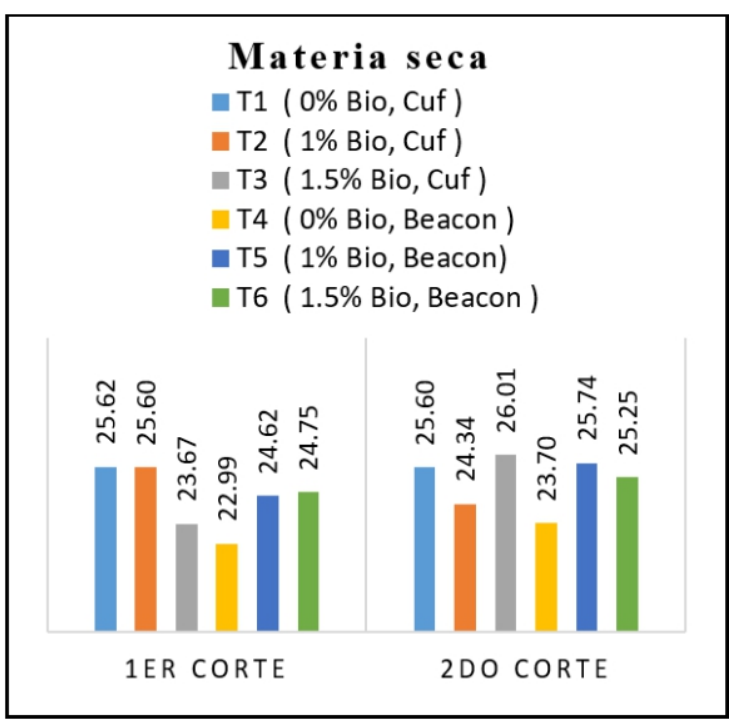

Figura 06. Contenido de materia seca del primer y segundo corte

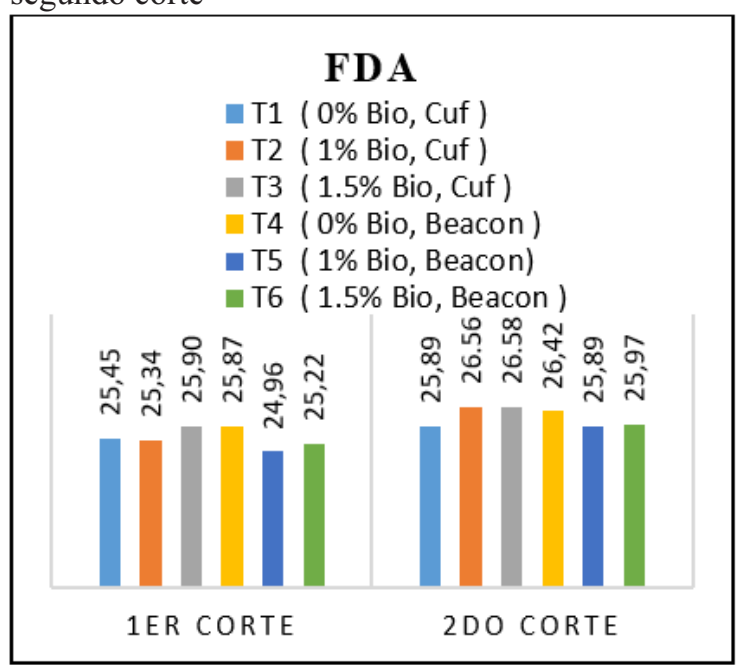

Figura 07. Porcentaje FDA del primer y segundo corte

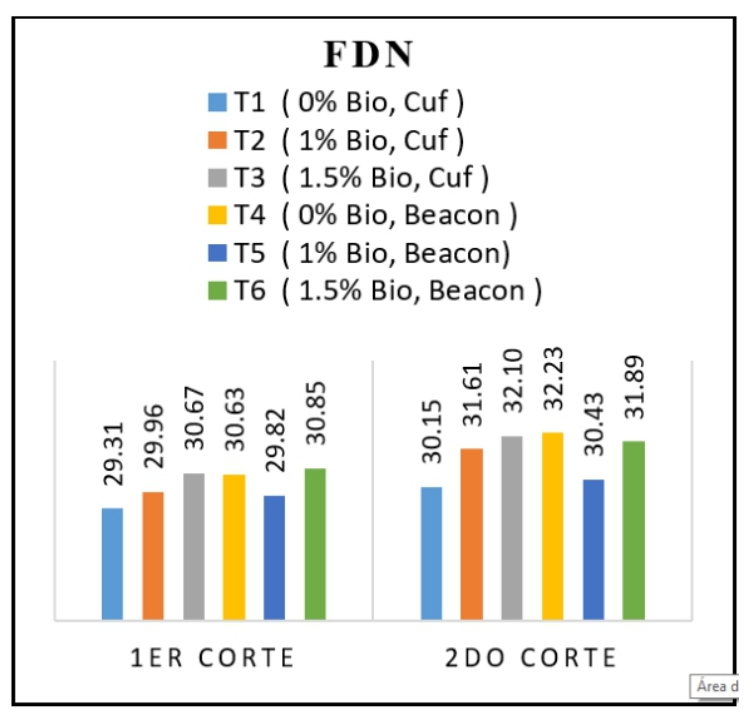

Figura 08. Porcentaje FDN del primer y segundo corte 


\section{DISCUSIÓN}

Sangay (2013) encontró valores de (1,19, 1,01 y 1,03 $\mathrm{kg} / \mathrm{m} 2$ ) con las variedades Alfamaster, Supersonic y Beacon, en la investigación se encontró mayores valores con 1.336 y $1.420 \mathrm{~kg} / \mathrm{m} 2$.Con respecto a la altura de planta de alfalfa, los valores encontrados son mayores a los reportados por Bayas, A. (2003), en su investigación reporta altura de planta promedio de $56.63 \mathrm{~cm}$ al utilizar biol en el cultivo de alfalfa. En la investigación, utilizando $1.5 \%$ de biofertilizante se obtuvo valores entre 61 y $66 \mathrm{~cm}$. Esto se relaciona a lo descrito por Cervantes, A. (2007), quien indica que los cultivos orgánicos proponen alimentar a los microrganismos del suelo para que estos a su vez de manera indirecta favorezcan a las plantas.

Con respecto al contenido de Materia Seca, se obtuvieron valores de 25,62 y $26,00 \%$ valores que están dentro del rango a los reportados por Castro y Chirinos (2007), quienes concuerdan en señalar que la alfalfa tiene entre 20 a $28 \%$ de materia seca, dependiendo de la época del año y de la edad de la planta.

En cuanto a proteína en estudios realizados por Capacho et al., (2018) obtuvo resultados de 4 variedades de alfalfas; Moapa 69, SW 8718, SW 8210 y Cuf 101 que fueron de 21.10, 20.40, 18.83 y $19.76 \%$ de contenido de proteína para las variedades de leguminosa. Los datos reportados en la investigación estuvieron entre $22,52 \%$ y $23.03 \%$ valores mayores a los mencionados anteriormente, las diferencias de los resultados obtenidos pueden variar por muchos factores como el lugar de siembra, fecha de siembra, piso ecológico, condiciones climáticas y otros.

La NRC (2007) menciona que los contenidos adecuados de fibra detergente acida son de $21 \%$ a $27 \%$ considerados como ideal para los rumiantes, asimismo menciona que la dieta de rumiantes debe contener al menos de 25 a $35 \%$ de fibra detergente neutra para asegurar un buen funcionamiento del rumen, la fibra detergente neutra consumida favorece a la producción de saliva. En tal contexto, los resultados de fibra detergente acida (25.903 y $26.577 \%)$ y neutra $(30.850 \%$ y $32.230 \%)$ obtenidas se encuentran dentro de los parámetros indicados por la NRC.

\section{CONCLUSIONES}

La investigación demuestra que al utilizar el biofertilizante al 1,5\% favorece en la obtención de mejores valores en rendimiento, altura de planta, número de hojas por planta, proteína, Fibra Detergente Neutro (FDN) y digestibilidad (DIVMS).

\section{REFERENCIAS BIBLIOGRÁFICAS}

Bayas, A. (2003). El bocashi, te de estiércol, biosol como biofertilizantes en la producción de alfalfa (Medicago sativa). Tesis de grado. Escuela de Ingeniería Zootécnica, Facultad de Ciencias Pecuarias - ESPOCH Riobamba Ecuador. pp. 28 - 54.

Blandón, S., Gallardo, A. y Llancys, A. (2013). Validación del mucílago de café para la producción de etanol y abono orgánico. Revista Tecnológica EL HIGO. Universidad Nacional de Ingeniería. Nicaragua.

Capacho Mogollón, A., Flórez-Delgado, D., y Hoyos-Patiño, J. (2018). Biomasa y calidad nutricional de cuatro variedades de alfalfa para introducir en Pamplona, Colombia. Ciencia y Agricultura. Vol. 15(1), 61-67

Castro, J y Chirinos, D (2007). Nutrición animal. Industria Gráfica edición. Huancayo Perú

Cervantes, A. (2007). Producción de pastizales en la Región Interandina del Ecuador. Manual $\mathrm{N}^{\mathrm{o}}$ 30. Quito, Ecuador. Edit. INIA. Pág. 10-22.

Crueger, W. Y Crueger A. (1993). Biotecnología: Manual de microbiología industrial. Tercera edición. Editorial ACRIBIA, S.A.-Royo, 2350006 Zaragoza. Mallorca- España. Pág.68.

Garassini, A. (1958). Microbiología caracas: U.C.V Organización de Bienestar Estudiantil, Venezuela.

Guccione, L. (2009). Tratamiento de los residuos orgánicos del comedor universitario de la UNALM para su uso como alimento para cerdos en crecimiento. Tesis de Ingeniero Ambiental. Biblioteca Agrícola Nacional, código: Q70 G9-T. UNALM. Lima- Perú. 122 p.

NRC. (2007). Nutrient requirement of small ruminants: Sheep, Goats, Cervids, and new world camelids. National Research Council, National Academic Press, Washin

Peralta, R. (2010). Determinación de parámetros óptimos en la producción de fast biol usandolas excretas del ganado lechero del establo de la UNALM.Tesis para optar por el título de Biólogo. Facultad de Ciencias: Universidad Nacional Agraria La Molina.Lima-Perú. 
Restrepo, J. (2007). Biofertilizante preparados y fermentados a base de excretas de vaca. Manual práctico. Primera edición. Volumen 2. Cali-Colombia. Págs. 17-18, 53-60.

Rodríguez, N. (2010). Estudio de un biosistema integrado para el pos tratamiento de las aguas residuales del café utilizando macrófitas acuáticas. Tesis para optar el grado de Doctor. Facultad de Ingeniería hidráulica y Medio Ambiente: Universidad Politécnica de Valencia-Valencia.

Rodríguez y Córdova, (2006). Manual de compostaje municipal. Tratamiento de residuos sólidos urbanos. S y $\mathrm{G}$ editores. Coyoacán-México.

Román, C. (2012). Tratamiento biológico de la cuyinaza a través de un proceso de fermentación homoláctica. Tesis Ingeniero Ambiental. Biblioteca Agrícola Nacional, código: F04R758-T. UNALM. Lima- Perú. Pág. 120-141.

Sangay, (2013). En la tesis "Evaluación productiva de gramineas y leguminosas, de última generación, en condiciones de la cuenca Cajamarquina" realizadas en el CIPP Huarapongo de la Facultad de Ingeniería en Ciencia Pecuarias, UNC.

Van Soest, P.J. (1967) Development of a Comprehensive System of Feed Analyses and Its Application to Forages. Journal of Animal Science, 26, 119-128. 